\title{
TECHNICAL STATE ASSESSMENT OF CHARGE EXCHANGE SYSTEM OF SELF-IGNITION ENGINE, BASED ON THE EXHAUST GAS COMPOSITION TESTING
}

\author{
Jacek Rudnicki \\ Ryszard Zadrąg \\ Gdansk University of Technology, Poland
}

\begin{abstract}
This paper presents possible use of results of exhaust gas composition testing of self - ignition engine for technical state assessment of its charge exchange system under assumption that there is strong correlation between considered structure parameters and output signals in the form of concentration of toxic compounds (ZT) as well as unambiguous character of their changes. Concentration of the analyzed ZT may be hence considered to be symptoms of engine technical state. At given values of the signals and their estimates it is also possible to determine values of residues which may indicate a type of failure. Available tool programs aimed at analysis of experimental data commonly make use of multiple regression model which allows to investigate effects and interaction between model input quantities and one output variable. Application of multi-equation models provides great freedom during analysis of measurement data as it makes it possible to simultaneously analyze effects and interaction of many output variables. It may be also implemented as a tool for preparation of experimental material for other advanced diagnostic tools such as neural networks which, in contrast to multi-equation models, make it possible to recognize a state at multistate classification and - in consequence - to do diagnostic inference. Here, these authors present merits of application of the above mentioned analytical tools on the example of tests conducted on an experimental engine test stand.
\end{abstract}

Keywords: diagnostic model, self-ignition engine, exhaust gas components, artificial neural networks

\section{INTRODUCTION}

During execution of engine running process, parameters of its structure undergo changes. It is not without any impact on its performance described by a set of output parameters. Mutual relation between engine structure parameters and output parameters makes it possible, in determined conditions, to take output parameters as engine technical state symptoms measured without its disassembling, because physical- chemical processes taking place during running process and quantities describing them can be generally observed and measured from outside. Amount of emission of exhaust gas components belongs a. o. to the quantities in question $[2,5,6,8]$.
Correct run of working cycle (especially run of combustion in engine cylinder) depends to a large extent on correctly working charge exchange system which has to ensure first of all effective discharging the combustion products and filling the working space with an required amount of air of appropriate quality.

Technical state identification of elements of charge exchange system is practically impossible in view of existing standard measurement equipment of engine. Known diagnostic methods are first of all based on the assessing of data concerning flow of working medium volume or mass and its losses in engine cylinders [11].

The following elements were taken to represent charge exchange system of typical ship engine (Fig. 1): 
- air filter;

- air compressor;

- air cooler;

- $\quad$ engine cylinders together with elements of air inlets and exhaust gas outlets;

- gas turbine.

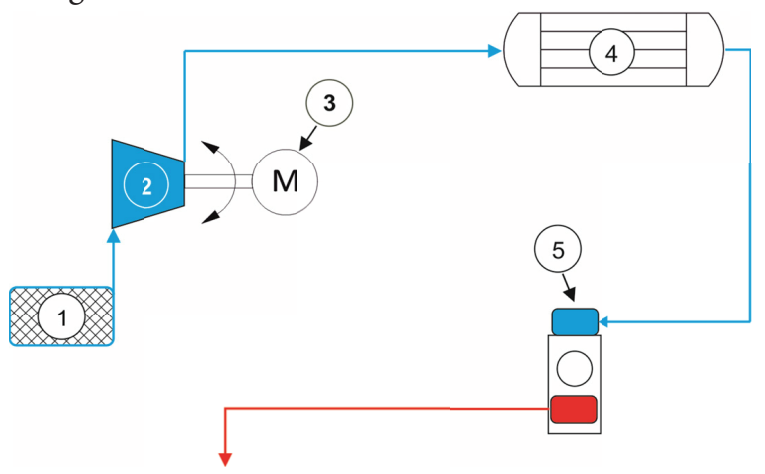

Fig. 1 Schematic functional diagram of engine charge exchange system. 1 - air filter, 2 - compressor, 3 - electric drive motor of air compressor, 4 - air cooler 5 - engine cylinders together with air inlet and exhaust gas outlet elements

\section{INITIAL ASSUMPTIONS}

On the basis of analysis of the set of quantities characterizing the charge exchange system an initial version of diagnostic table ( Tab. 1) and the system's topological model ( Fig. 2) was prepared [13].

In view of occurrence of many cases of intuitive determination of changes as well as due to rather not strong relations of the exhaust gas toxicity indices shown in Tab.1 with the engine running parameters and these with structure parameters ( failures), it is necessary to verify data of Tab. 1 empirically and determine the existing relations by simulation investigations.

Tab. 1 Initial diagnostic table for charge exchange system of self-ignition engine

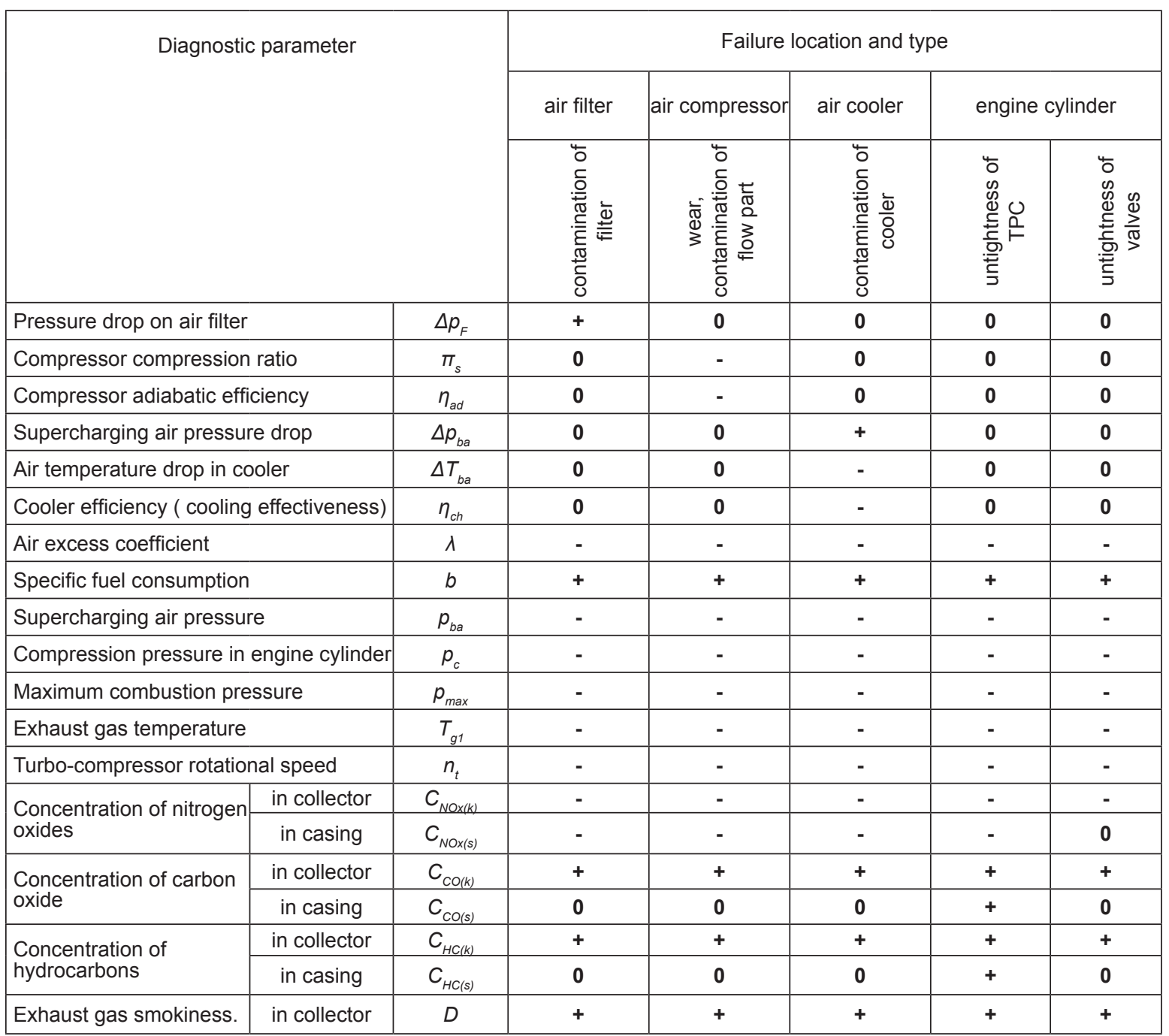

Notation:

"-" - decrease in value of a parameter; „+” - increase in value of a parameter; „0” - without any change.

Comment: The diagnostic parameters $\Delta p_{p}, \pi, \eta_{a p^{p}} \Delta p_{b a}, \Delta T_{b a}, \eta_{c h}, b$ are complex quantities determined on the basis of results of direct measurements. 


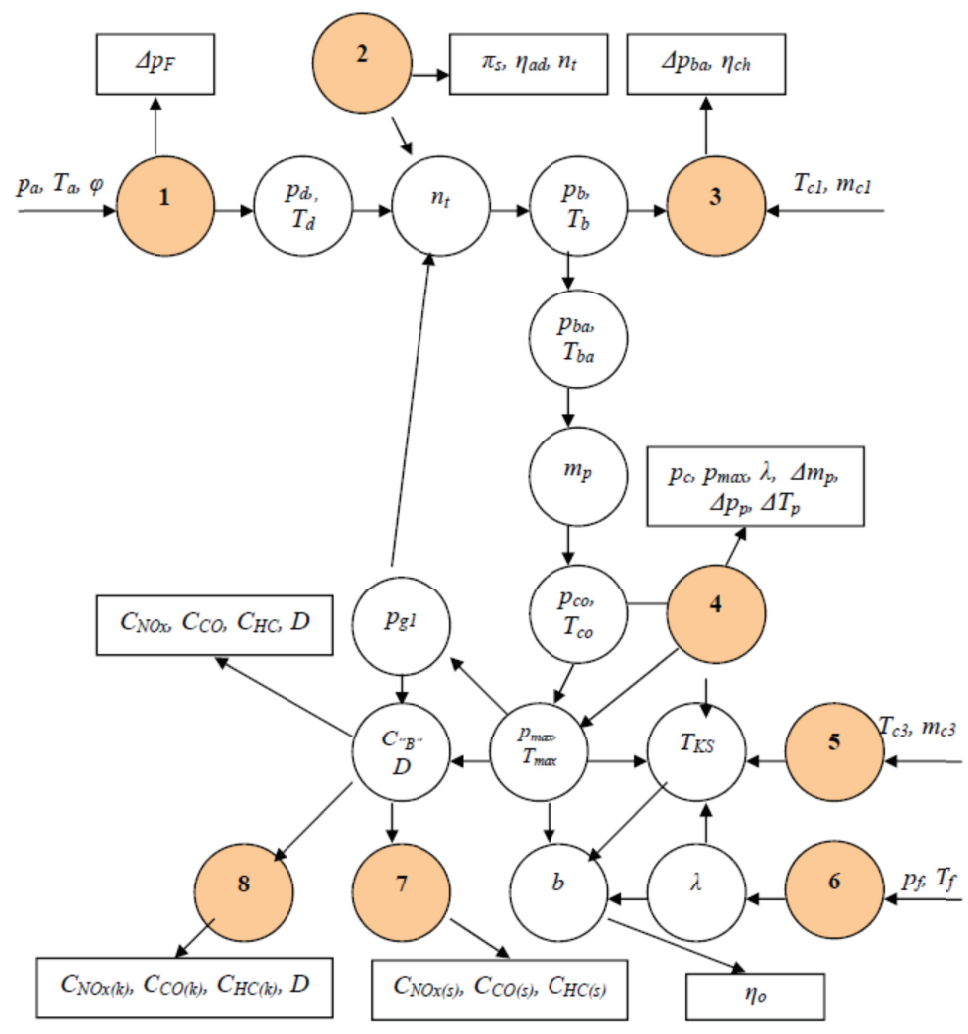

Fig. 2 Topological model of engine charge exchange system

1 - air filter 2 - compressor, 3 - air cooler, 4 - engine combustion chamber, 5 - fresh water cooler, 6 - injection apparatus, 7 - engine crankshaft casing, 8 - exhaust gas collector

\section{SET OF EMPIRICAL METHODS FOR SIMULATION INVESTIGATIONS ON CHARGE EXCHANGE SYSTEM}

Simulation investigations are mainly aimed at determining whether it is possible to identify state of charge exchange system on the basis of assessment of changes in exhaust gas toxicity indices, including the following [12]:

- verification of the parameters given in Tab. 1;

- verification of changes in values of diagnostic parameters, depending on location and type of unserviceability of elements of charge exchange system;

- $\quad$ determination ( detection) of connections (relations) of structure parameters of elements of charge exchange system with engine working parameters, and these with diagnostic parameters - exhaust gas toxicity indices;

- possible selection, out of exhaust gas toxicity indices , crucial diagnostic parameters, and, out of engine running indices, auxiliary ( verifying) diagnostic parameters of state of elements of engine charge exchange system.

The unserviceability types selected as a result of the performed analysis of elements of charge exchange system were simulated in the following way:

- contamination of air filter - by throttling partly (shadowing) its active surface $\mathrm{p}_{\mathrm{f}}$;
- wear or contamination of compressor flow part - by throttling partly air at inlet $\mathrm{p}_{\mathrm{s}}$;

- untightness of piston - rings - cylinder unit - by grinding partly sealing surface of rings as well as enlarging the piston-ring joints to get assumed values of the cross-section area of untightness $\mathrm{S}_{\mathrm{u}}$;

- $\quad$ untightness of inlet and outlet valves - by grinding partly fying face to get assumed values of the cross-section area of untightness $\mathrm{S}_{z}$.

The approximate wear values given in Tab. 2 served as a basis for preparation of the specified unserviceability events to be used in basic simulation investigations. The way of their preparation consisted in the following:

removal (e.g. by grinding or machining) given volumes of material out of surfaces of cooperating elements of combustion chamber space , which correspond to preliminarily calculated wear values or result from experimental data ( verifying data from repair workshop),

- $\quad$ execution of preliminary tests in respect to unserviceability events which decide on quality of filling. The percentage changes in the air flow drag ps $(0 ; 33,3 \%)$ result from the air volume fluxes at clean $\left(\mathrm{V}=0,12 \mathrm{~m}^{3} / \mathrm{s}\right)$ and contaminated $(\mathrm{V}=0,08$ $\mathrm{m}^{3} / \mathrm{s}$ ) flow part of air compressor. And, the changes in the air flow drag pf $(0 ; 50 \%)$ result from the difference between the air filter active surface of clean flow $\left(4071,5 \mathrm{~mm}^{2}\right)$ and that contaminated $\left(2035,75 \mathrm{~mm}^{2}\right)$.

In view of a vast range of necessary experimental measurements, resulting from the aim of simulation investigations, it was assumed, like in case of fuelling system testing, to carry out laboratory tests aided by experiment planning theory $[4,7]$ as well as the computer software STATISTICA PL.

1. The set of input data $X$ :

$x_{1}$ - engine rotational speed $n[\mathrm{rpm}]$;

$x_{2}$ - engine torque $T_{\mathrm{tq}}[\mathrm{N} \times \mathrm{m}] ;$

$x_{3}-$ air filter contamination $p_{\mathrm{F}}[\%]$;

$x_{4}$ - contamination of compressor flow part $p_{\mathrm{s}}[\%]$;

$x_{5}$ - untightness of TPC unit $S_{\mathrm{u}}[\mathrm{mm} 2]$;

$x_{6}$ - untightness of valves $S_{\mathrm{z}}[\mathrm{mm} 2]$.

2. The set of output data $Z$ :

$z_{1}$ - engine power $P_{\mathrm{i}}[\mathrm{kW}]$;

$z_{2}-$ air excess ratio $\lambda$;

$z_{3}$ - hourly fuel consumption $B[\mathrm{~g} / \mathrm{h}]$

$z_{4}$ - maximum pressure in injection pipe $p_{\mathrm{wtr}(\max )}$;

$z_{5}$ - maximum compression pressure $p_{\mathrm{c}(\max )}[\mathrm{MPa}]$;

$z_{6}-$ cylinder exhaust gas temperature $T_{\mathrm{g} 1}[\mathrm{~K}]$;

$\mathrm{z}_{7}$ - mean indicated pressure $p_{\mathrm{mi}}[\mathrm{MPa}]$;

$z_{8}$ - compression pressure in the instant of fuel injection $p_{c}[\mathrm{MPa}]$

$z_{9}$ - maximum combustion pressure $\mathrm{p}_{\max }[\mathrm{MPa}]$

$z_{10}$ - carbon oxide concentration within exhaust gas outlet collector $C_{\mathrm{CO}(\mathrm{k})}[\mathrm{ppm}]$; 
Tab. 2. Input data in the plan of experimental test on charge exchange system

\begin{tabular}{|c|c|c|c|c|c|c|}
\hline \multirow{2}{*}{ No. } & \multirow{2}{*}{ Input quantity } & \multirow{2}{*}{ Notation } & \multirow{2}{*}{ Dimension } & \multicolumn{2}{|c|}{ Values of input quantities } & \multirow{2}{*}{ Remarks } \\
\hline & & & & $\min (-1)$ & $\max (+1)$ & \\
\hline 1 & Rotational speed & $\mathrm{n}$ & $\mathrm{rpm}$ & 850 & 1100 & \\
\hline 2 & Torque & $\mathrm{T}_{\mathrm{tq}}$ & $\mathrm{N} \cdot \mathrm{m}$ & 0 & 77 & \\
\hline 3 & $\begin{array}{l}\text { Untightness of rings of TPC } \\
\text { unit }\end{array}$ & $\mathrm{S}_{\mathrm{u}}$ & $\mathrm{mm}^{2}$ & 0,57 & 1,178 & $\begin{array}{c}\text { grinding sealing surface and } \\
\text { joint }\end{array}$ \\
\hline 4 & $\begin{array}{l}\text { Untightness of inlet and } \\
\text { outlet valves. }\end{array}$ & $\mathrm{S}_{\mathrm{z}}$ & $\mathrm{mm}^{2}$ & 0 & 0,75 & $\begin{array}{c}\text { Groove in fying face of inlet } \\
\text { and outlet valve }\end{array}$ \\
\hline 5 & $\begin{array}{l}\text { Flow drag increase within } \\
\text { filter }\end{array}$ & $\mathrm{p}_{\mathrm{F}}$ & $\%$ & 0 & 50 & Flow throttling \\
\hline 6 & $\begin{array}{l}\text { Flow drag increase within } \\
\text { flow part of compressor }\end{array}$ & $\mathrm{p}_{\mathrm{s}}$ & $\%$ & 0 & 33 & Flow throttling \\
\hline
\end{tabular}

$\mathrm{Z}_{11}$ - carbon oxide concentration within crankshaft casing $C_{\mathrm{CO}(\mathrm{s})}[\mathrm{ppm}]$

$\mathrm{z}_{12}$ - concentration of hydrocarbons within exhaust gas outlet collector $C_{\mathrm{HC}(\mathrm{k})}$ [ppm];

$z_{13}$ - concentration of hydrocarbons within crankshaft casing $C_{H C(s)}[p p m]$;

$z_{14}$ - nitrogen oxides concentration within exhaust gas outlet collector $C_{\text {NOx }(k)}[\mathrm{ppm}]$;

$z_{15}$ - nitrogen oxides concentration within crankshaft casing $C_{\text {NOx }(s)}[\mathrm{ppm}]$

$z_{16}$ - oxygen concentration in exhaust gas $C_{\mathrm{O} 2}[\%]$;

$z_{17}$ - pressure increase rate in cylinder $(\Delta p / \Delta \alpha) s$;

$z_{18}$ - indicated specific fuel consumption $b i$;

$z_{19}$ - engine indicated efficiency $\eta_{i}$

3. The set of the constants, $C$, which may occur during measurements and have influence on changes in output quantities $Z$ (e.g. resulting from a used kind of fuel oil , lubricating oil ). As assumed, the experimental investigations will be short-lasting and carried out in similar conditions, i.e. they will be not taken into account in the experiment plan and it should deal only with one measurement block.

4. The set of the disturbing quantities, $H$, which may undergo changes during execution of the experiment:

$h_{1}$ - ambient temperature $t_{a}[o C]$;

$h_{2}$ - atmospheric pressure $p_{a}[h P a]$;

$h_{3}$ - relative humidity of air in the laboratory $\varphi[\%]$.

\section{STATISTICAL ANALYSIS OF RESULTS OF THE EXPERIMENT}

In view of the assumed linear model of influence of charge exchange system structure parameters on engine working indices, especially concerning exhaust gas components, a simplified statistical analysis of results of the experiment was performed. As a result of the analysis the following was obtained:

- approximating polynomials (functions of the experiment's object) describing functional model of charge exchange system;

- assessment of main effects and interactions of the determined ( assumed) model;

- correlation of input and output quantities describing the experiment's object;

- assessment of adequacy of function of the experiment's object.

Based on an analysis of the models possible to be used and the data given in Tab. 3, was assumed a model which takes into account two-factor interactions, despite more favourable values of the basic coefficients $\left(\mathrm{R}^{2}, \mathrm{MS}\right)$ for estimation of representation (approximation) of relations between input and output quantities of the experiment's object, with taking into account interactions of a higher order, e.g. three-factor ones $[3,14]$.

As results from the data of Tab. 3 , the model with three-factor interactions covers entirely all the relations ( variations) between input and output quantities (the coefficient of determination $\mathrm{R}^{2}=1$ ), which simultaneously means that no residues are rejected and they are not taken into account in the model ( $\mathrm{MS}=0)$. However , as results from mathematical description of any empirical relation, its accuracy increases along with number of interactions which contribute simultaneously to increasing confounding of approximated relations. Hence, confounding degree influences clarity of subject-matter analysis of describing problem ( phenomenon ) and, consequently, may lead to incorrect conclusions and decisions. In such cases, as a result of the confounding ( especially multi-factor one), obtained calculation results are often incorrect and inconsistent with both theoretical physical principles and empirical reality of a phenomenon under investigation. Therefore, taking into account minor differences between values of the analyzed statistical measures, one assumed the model of two-factor interactions for subject-matter analysis. For the models, were determined approximating polynomials for output quantities 
Tab. 3 Set of values of selected statistical measures for empirical functional models of charge exchange system

\begin{tabular}{|c|c|c|c|c|c|c|}
\hline \multirow{2}{*}{$\begin{array}{c}\text { Output } \\
\text { quantities }\end{array}$} & \multicolumn{2}{|c|}{ Model without interactions } & \multicolumn{2}{|c|}{ Model with two-factor interactions } & \multicolumn{2}{|c|}{$\begin{array}{c}\text { Model with three-factor } \\
\text { interactions }\end{array}$} \\
\hline & $\mathrm{R}^{2}$ & MS & $\mathrm{R}^{2}$ & MS & $\mathrm{R}^{2}$ & MS \\
\hline B & 0,009662 & 0,009663 & 0,99766 & 0,00114 & 1 & 0 \\
\hline $\mathrm{A} / \mathrm{F}$ & 0,93843 & 18,2333 & 0,97808 & 29,2124 & 1 & 0 \\
\hline$\lambda$ & 0,93752 & 0,08526 & 0,97774 & 0,13666 & 1 & 0 \\
\hline $\mathrm{C}_{\mathrm{CO}(\mathrm{k})}$ & 0,87006 & 97291 & 0,99916 & 2816,31 & 1 & 0 \\
\hline $\mathrm{C}_{\mathrm{CO}(\mathrm{s})}$ & 0,56833 & 16,583 & 0,87708 & 21,2500 & 1 & 0 \\
\hline $\mathrm{C}_{\mathrm{HC}(\mathrm{k})}$ & 0,81543 & 1501,49 & 0,99677 & 210,125 & 1 & 0 \\
\hline $\mathrm{C}_{\mathrm{HC}(\mathrm{s})}$ & 0,70837 & 1126,9 & 0,99998 & 0,5000 & 1 & 0 \\
\hline $\mathrm{C}_{\mathrm{NOx}(\mathrm{k})}$ & 0,88088 & 1102,3 & 0,95341 & 19,400 & 1 & 0 \\
\hline $\mathrm{C}_{\mathrm{CO} 2(\mathrm{k})}$ & 0,97955 & 0,13079 & 0,99512 & 0,14051 & 1 & 0 \\
\hline $\mathrm{C}_{\mathrm{O} 2}$ & 0,97314 & 0,38387 & 0,99593 & 0,26153 & 1 & 0 \\
\hline $\mathrm{t}_{\mathrm{g} 1}$ & 0,95357 & 757,25 & 0,99786 & 157,250 & 1 & 0 \\
\hline $\mathrm{p}_{\mathrm{c}}$ & 0,7297 & 0,0244139 & 0,99775 & 0,0009125 & 1 & 0 \\
\hline $\mathrm{p}_{c(\max )}$ & 0,84452 & 0,0292583 & 0,99272 & 0,0061625 & 1 & 0 \\
\hline $\mathrm{p}_{\mathrm{mi}}$ & 0,88763 & 4562,319 & 0,98978 & 3321,125 & 1 & 0 \\
\hline $\mathrm{p}_{\max }$ & 0,85422 & 0,0258563 & 0,99811 & 0,0015062 & 1 & 0 \\
\hline$b_{i}$ & 0,50217 & 690,7553 & 0,98854 & 127,2012 & 1 & 0 \\
\hline
\end{tabular}

describing state of investigated engine with unserviceable charge exchange system as well as statistical correlations between input and output variables of the experiment's object. The determined approximating polynomials make it possible to determine any relation between particular variables and also to calculate and estimate influence of introduced (simulated) failures (wear) of elements of charge exchange system on engine running and toxicity indices. It may be also assumed that it would be possible to determine mutual relations between structure parameters and exhaust gas toxicity indices - directly or indirectly through engine running indices. As assumed, it will be this way possible to reveal, out of exhaust gas components, diagnostic parameters for given engine fuelling elements or units . Correctness of the assumption is confirmed by the existing relationships ( correlations) between wear of elements of charge exchange system and concentration of toxic components in engine exhaust gas.

\section{CONCEPT OF A NEURAL DIAGNOSTIC SYSTEM}

Since the form of approximating polynomials for output quantities describing state of investigated engine with unserviceable charge exchange system is complex, an applicable alternative may be a neural approximating model which, based on experimental results as well as determined coefficients of approximating polynomials, may be applied to the modelling of arbitrary nonlinearity and which is highly resistant against disturbances $[1,9,10]$.

A condition for reaching correct responses from used neural networks is appropriately numerous set of learning data. To work out such a set can be made possible by using the above described approximating polynomials.
For the purposes of the simulation investigations whose results are presented in the further part of this paper, a general schematic diagram of neural failure detection system was worked out under the following assumptions :

- the system identifies the following classes of engine technical states:

- the class of states $\mathrm{S}_{0}$ - technically serviceable engine,

- the class of states $S_{1}$ - untightness of sealing rings,

- the class of states $S_{2}$ - untightness of inlet and/or outlet valves,

- the class of states $S_{3}$ - increase of flow drag within air filter,

- the class of states $S_{4}$ - increase of drag within flow part of air compressor,

- for each of the class of states of technically unserviceable engine will be worked out a separate neural sub-network (4 sub-networks in total) which generates, at its outlet, the value „True” (1) - in case of identification of a dedicated class of states or the value „False” (0) - in the opposite case. The schematic diagram of separate sub-network is shown in Fig. 3

- the engine torque $\mathrm{T}_{\mathrm{tq}}$ and engine rotational speed $\mathrm{n}$ were assumed to be independent variables (input parameters),

- parameters under diagnostic surveillance:

- exhaust gas temperature tg1,

- concentration of nitrogen oxides within exhaust gas collector, $C_{\mathrm{NOx}(\mathrm{k})}$,

- concentration of carbon oxide within exhaust gas collector, $C_{\mathrm{CO}(\mathrm{k})}$,

- concentration of hydrocarbons within exhaust gas collector, $C_{\mathrm{HC}(\mathrm{k})}$,

concentration of oxygen in exhaust gas, $C_{\mathrm{O} 2}$,

- for each of the parameters a neural model will be worked out and all the models prepared this way 


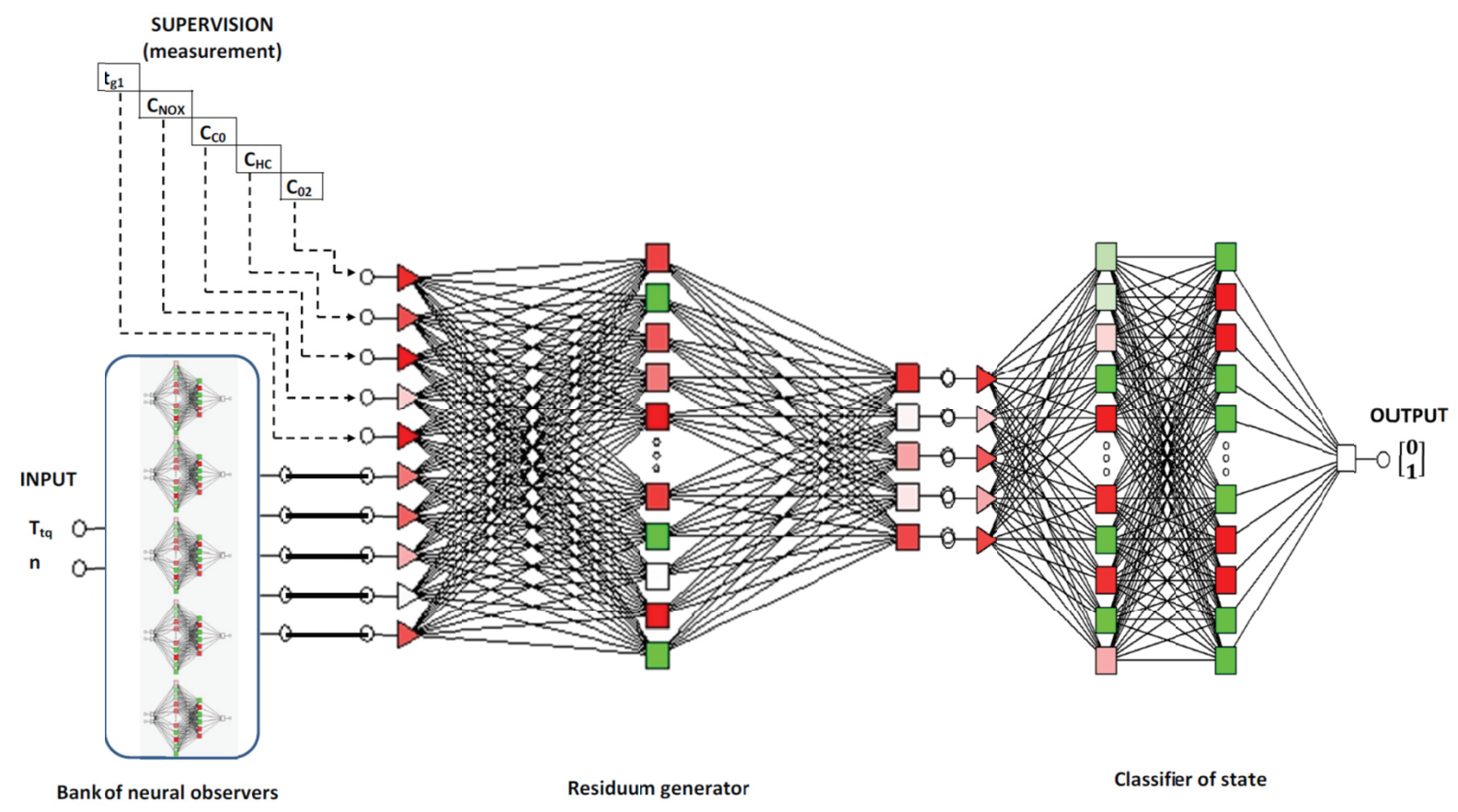

Fig. 3 Schematic diagram of the neural subsystem for detection of the state $S i,(i=0,1, \ldots 4)$

will form the so-called bank of neural observers $[1,8]$, intended for the modelling of values of the considered parameters in normal (free of failures ) engine running state,

- by comparing output signals from the model and diagnosed engine, residues, i.e. signals representing discrepancies between model and engine, will be determined,

- the obtained vector of residues $r=\left[\begin{array}{lll}r_{1} & \ldots & r_{5}\end{array}\right]$ will be analyzed by a neural classifier of residues whose task will be to determine if a failure occurred - in such case the value "True" (1) will be generated at its output, otherwise the system will generate the value "False" (0),

- the vector $\mathrm{a}=\left[\begin{array}{lll}w_{1} & \ldots & w_{4}\end{array}\right](\mathrm{wi}=0 \cup 1)$ achieved as a result of action of the entire system (4 sub-networks), will constitute a diagnostic information source (e.g. in case of obtaining the vector $\left[\begin{array}{llll}0 & 0 & 0 & 0\end{array}\right]$ there exist premises to consider the current state of engine as that belonging to the class of states $\mathrm{S}_{0}$ etc)

The results presented in the further part of the paper was limited to only one sub-network - in this case - to the network which identifies occurrence of the class of states $S_{1}$

\section{RUN AND RESULTS OF SIMULATION INVESTIGATIONS}

The results obtained in the form of approximating polynomials of output quantities describing state of considered engine with unserviceable charge exchange system, were used for working out the set of learning data for particular sub-networks.
In the case in question the form of the polynomials is as follows :

$$
\left[y_{i}\right]=\left[B_{i}\right]+\left[x_{k}\right] \cdot\left[A_{k, i}\right]
$$

where :

$\left[\mathrm{y}_{\mathrm{i}}\right]-$ column vector of parameters under diagnostic surveillance $(i=1,2, \ldots 5)$ :

$\mathrm{y}_{1}$ - exhaust gas temperature $-t_{\mathrm{g} 1}$,

$\mathrm{y}_{2}$ - concentration of nitrogen oxides in exhaust gas - $C_{\mathrm{NOx}}$,

$\mathrm{y}_{3}$ - concentration of carbon oxide in exhaust gas - $C_{\mathrm{CO}}$,

$\mathrm{y}_{4}$ - concentration of hydrocarbons in exhaust gas - $C_{\mathrm{HC}}$,

$\mathrm{y}_{5}$ - s concentration of oxygen in exhaust gas $-C_{\mathrm{O} 2}$.

$\left[\mathrm{B}_{\mathrm{i}}\right]$ - column vector of constants appearing in approximating polynomials:

$$
B=\left[\begin{array}{c}
121,319 \\
257,584 \\
2584,68 \\
-114,491 \\
10,67619
\end{array}\right]
$$

$\left[\mathrm{x}_{\mathrm{k}}\right]$ - row vector of input variables:

$x=\left[n T_{t q} p_{f} p_{s} S_{u} S_{z} I_{12} I_{13} I_{14} I_{15} I_{16} I_{34} I_{36}\right]$

where:

$\mathrm{I}_{\mathrm{jk}}-$ regression coefficients concerning interactions $\mathrm{y}_{\mathrm{j}} \rightarrow \mathrm{y}_{\mathrm{k}}$ 
$\left[\mathrm{A}_{\mathrm{j}, \mathrm{k}}\right]$-matrix of regression coefficients of approximating polynomials

\begin{tabular}{|c|c|c|c|c|c|}
\hline & $\mathrm{C}_{\mathrm{CO}(\mathrm{k})}$ & $\mathrm{C}_{\mathrm{BC}(\mathrm{L})}$ & $\mathrm{C}_{\mathrm{NO} \mathrm{x}(\mathrm{k})}$ & $\mathrm{C}_{02}$ & $t_{31}$ \\
\hline$n$ & $-2,45$ & $-0,207$ & $-0,147$ & 0,00528 & 0,070 \\
\hline$T_{\text {tq }}$ & $-23,55$ & $-0,929$ & 0,736 & $-0,03629$ & $-0,661$ \\
\hline$p_{f}$ & 2,72 & 0,108 & 3,205 & 0,00385 & 0,316 \\
\hline$p_{s}$ & $-8,05$ & $-2,828$ & 3,245 & 0,01413 & 1,380 \\
\hline$S_{u}$ & $-1682,73$ & 10,855 & $-118,832$ & 2,26151 & 46,546 \\
\hline$S_{z}$ & $-1760,37$ & $-215,56$ & $-206,267$ & 3,79633 & $-127,80$ \\
\hline$I_{12}$ & 0,04 & 0,003 & 0,001 & $-0,00004$ & 0,003 \\
\hline$I_{13}$ & 0,01 & 0,001 & $-0,003$ & $-0,00003$ & 0,001 \\
\hline$I_{14}$ & 0,02 & 0,004 & $-0,002$ & $-0,00004$ & $-0,000$ \\
\hline$I_{15}$ & 1,65 & 0,048 & 0,115 & $-0,00206$ & $-0,046$ \\
\hline$I_{16}$ & 2,01 & 0,284 & 0,176 & $-0,00428$ & 0,155 \\
\hline$I_{34}$ & $-0,10$ & $-0,003$ & $-0,027$ & 0,00059 & $-0,021$ \\
\hline$I_{36}$ & $-6,35$ & $-2,007$ & 0,707 & 0,01807 & $-0,813$ \\
\hline
\end{tabular}

In connection with that five parameters subjected to real time control were selected, it become necessary, in line with the assumed concept, to form the same number of neural models representing relationship between the input variables $: T_{\text {tq }}$ and $n$, and variables subjected to diagnostic surveillance in the state considered normal, i.e. the state $\mathrm{s}_{0}$.

The first stage of the work consisted in running preliminary investigations aimed at selection of type and optimum structure of neural networks of particular models. To this end, were applied automatic tools of the software STATISTICA Neural Networks $v .7 .0$ aiding in the testing of neural networks used for data analysis and prediction issues [15].

The aim of training the networks was to reach such state of them, which determines correct reaction in the broad range of input functions which, in this case, are various values of engine load (in the range of $0 \div 77 \mathrm{Nm}$ ) and rotational speed $(850 \div 1100 \mathrm{rpm})$, introduced to inputs. The worked out by using approximating polynomials - learning set covered 19578 cases in relation to each of the five parameters. The example realizations of changes in values (cases : $C_{\mathrm{NOx}}$ and $\left.t_{\mathrm{g} 1}\right)$ in function of engine torque and rotational speed are presented in Fig. 4 and 5.

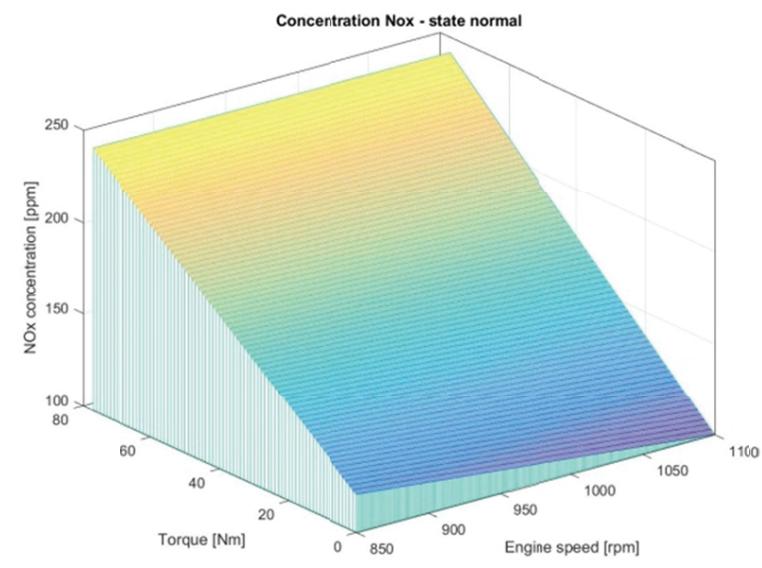

Fig. 4. The functional relationship between $C_{N O X}$ and $\left(T_{t q}, n\right)$

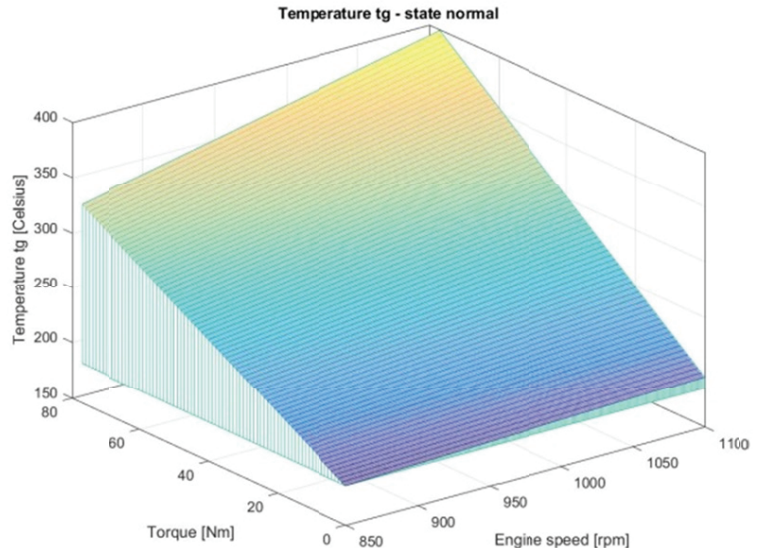

Fig. 5 The functional relationship between tg1 and (Ttq, $n$ )

As a result of the performed simulations and analysis of their results, the network of the type : multilayer perceptron with one hidden layer, was selected.

The stage of preliminary investigations made it possible to perform the basic training of networks for each case of neural observer modelling changes in selected variables. The training and final architecture of the networks was realized by means of the software MATLAB 2015b and its dedicated extension „Neural Network Toolbox” [16].

Application of the basic quality measure for the worked - out neural models, i.e. values and distribution of residues and percentage errors between values expected at output from networks and its real response, showed adequate quality of representation and negligible, from practical point of view, differences. The next stage was aimed at the working out of structure and training of residues generator. For each of the considered class of states, the task of the residues generator is to determine values of differences between monitored output signals of the diagnosed engine, $y_{i}=f\left(T_{t q}, n\right)$, and values of responses, corresponding with them, from the side of the worked out neural observers bank, $y_{\text {is }}=f\left(T_{t q}, n\right)$. For the presented case of the class of states $\mathrm{S}_{1}$ :

- exhaust gas temperature $t_{\mathrm{g} 1}-\mathrm{y}_{1}$,

- concentration of nitrogen oxides in exhaust gas, $C_{\mathrm{NO} x}{ }^{-}$ $\mathrm{y}_{2}$,

- concentration of carbon oxide in exhaust gas, $C_{\mathrm{CO}}-\mathrm{y}_{3}$,

- concentration of hydrocarbons in exhaust gas, $\mathrm{y}_{4}$,

- concentration of oxygen in exhaust gas, $C_{O 2}-y_{5}$,

- neural model response, $\mathrm{t}_{\mathrm{g} 1 \mathrm{~s}}-\mathrm{y}_{1 \mathrm{~s}}$,

- neural model response $C_{\mathrm{NOxs}}-\mathrm{y}_{2 \mathrm{~s}^{\prime}}$

- neural model response $C_{\mathrm{COs}}-\mathrm{y}_{3 \mathrm{~s}^{\prime}}$

- neural model response $C_{\mathrm{HCs}}-\mathrm{y}_{4 \mathrm{~s}^{\prime}}$

- neural model response $C_{\mathrm{O} 2 \mathrm{~s}}-\mathrm{y}_{5 \mathrm{~s}^{\prime}}$

The vector of residues $r=\left[r_{1}, r_{2}, r_{3}, r_{4}, r_{5}\right]$, obtained this way , may be considered a signal which contains information on occurred failures (in this case - untightness of sealing rings). During the engine running in the state taken as normal (the class of states $\mathrm{S}_{0}$ ), components of the obtained vector of residues 
should be close to zero, but in the case of failure occurrence the difference becomes significantly greater.

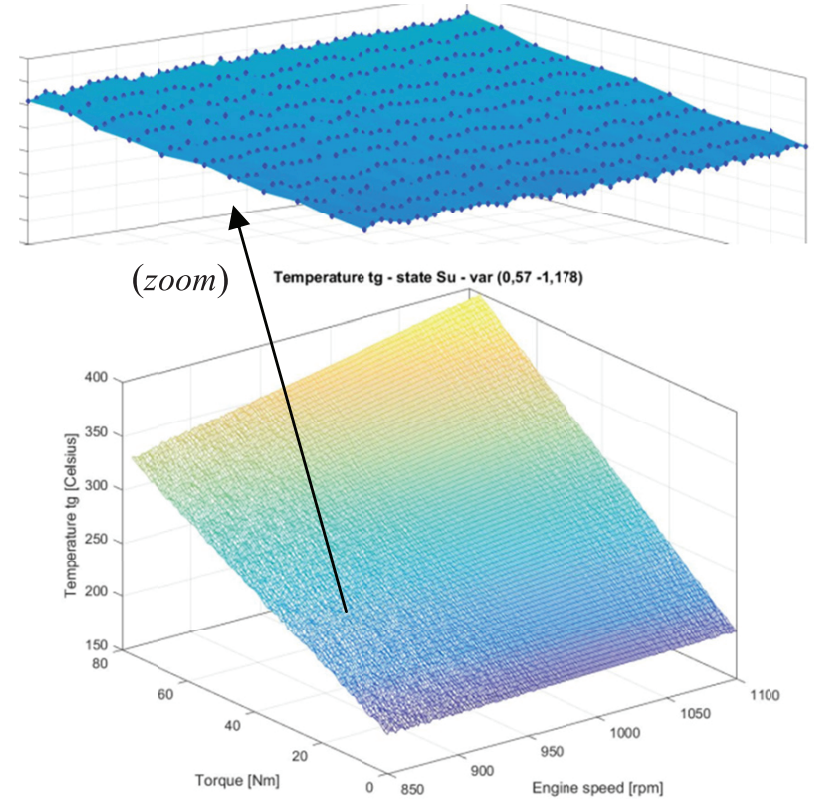

Fig. 6 The functional relationship between $t_{g 1}$ and $\left(T_{t q^{\prime}} n\right)$ - class of states $S_{1}$ $\left(S_{u} \in<0,57,1,178>^{g 1}\left[\mathrm{~mm}^{2}\right]\right)$

The learning sets worked out with the use of approximating polynomials, contained about 20000 cases with reference to each of the five parameters. For the presented case of the class of states $S_{1}$, the set of model responses $y_{\text {is }}=f\left(T_{t q}, n\right)$ was worked out for random changes in the values $S_{u}$ within the range of $0,7 \div 1,178 \mathrm{~mm}^{2}, \mathrm{n}$ - values within the range of $850 \div 1100 \mathrm{rpm}, \mathrm{T}_{\mathrm{tq}}$ - values within the range of $0 \div 77 \mathrm{Nm}$. Fig. 6 exemplifies the relationships $\mathrm{y}_{1 \mathrm{~s}}=\mathrm{f}\left(\mathrm{T}_{\mathrm{tq}}, \mathrm{n}\right)$ for the class of states $\mathrm{S}_{1}$.

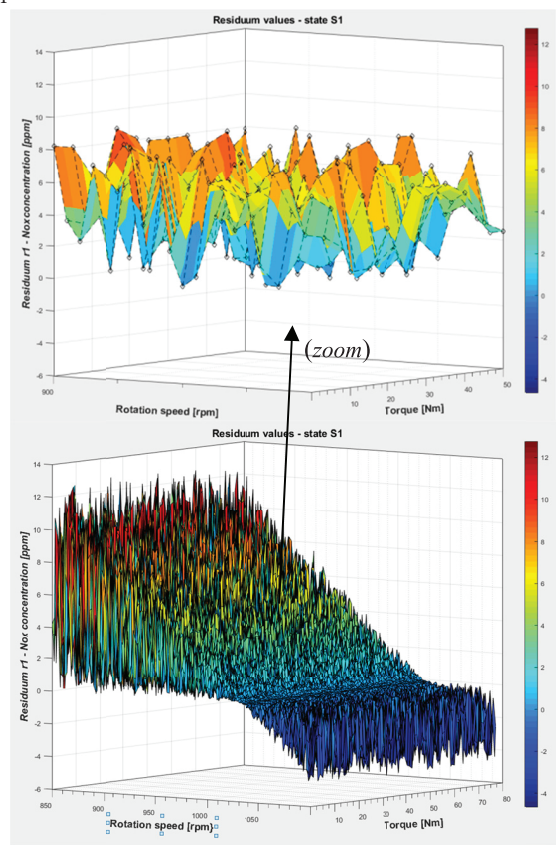

Fig. 7 Values of the residues $r_{2}\left(\mathrm{NO}_{x}\right.$ concentration $)$ - the class of states $S_{1}$.
Based on experience dealing with optimum network structure and type, it was decided to select a linear neural network which models relations between its ten inputs $\left(\mathrm{y}_{1}, \mathrm{y}_{2}\right.$, $\left.\mathrm{y}_{3}, \mathrm{y}_{4}, \mathrm{y}_{5}, \mathrm{y}_{1 \mathrm{~S}}, \mathrm{y}_{2 \mathrm{~S}}, \mathrm{y}_{3 \mathrm{~S}}, \mathrm{y}_{4 \mathrm{~S}}, \mathrm{y}_{5 \mathrm{~S}}\right)$ and five outputs $\left(\mathrm{r}_{1}, \mathrm{r}_{2}, \mathrm{r}_{3}, \mathrm{r}_{4}, \mathrm{r}_{5}\right)$. The results achieved in the case of the class of states $\mathrm{S}_{1}$, are shown for the parameter $\mathrm{C}_{\mathrm{NOx}}$ in Fig. 7.

Like in the case of the neural observers bank, the test of the network and application of its quality measure in the form of values and distribution of modules of the residues between values expected at network's output and its real response, showed very good quality of representation and negligible, from practical point of view, differences. Fig. 8 presents an example result for the class of states $S_{1}$.

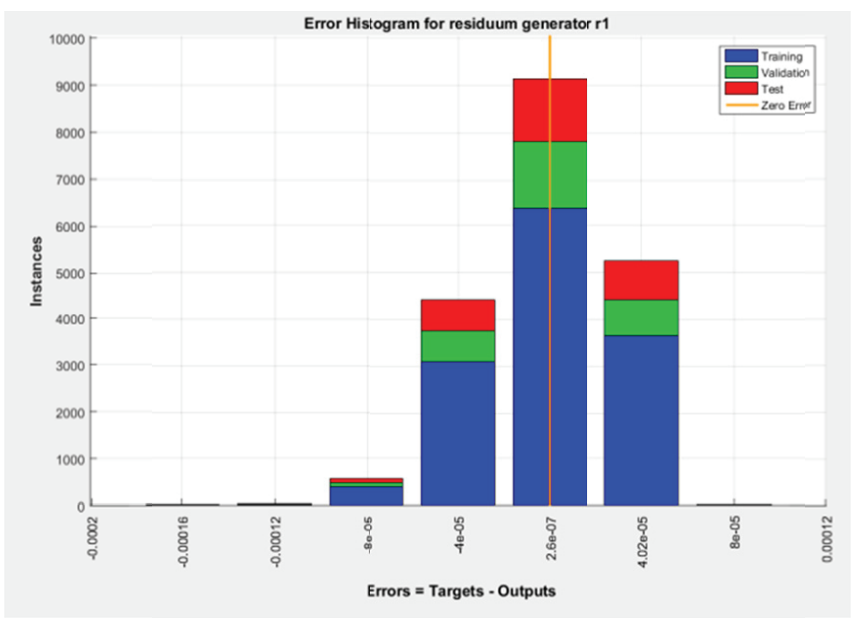

Fig. 8 Distribution of modules of absolute errors of residues generator - the class of states $S_{1}$

The task of the last element of failure detection and location system, i.e. the state classifier (block of residues evaluation), is to analyze residue's vector in order to determine whether a selected failure has occurred or not. This is a typical classification issue consisting in the matching of vector's symptoms to one of the distinguished classes of states.

Based on the $1^{\text {st }}$ stage of investigations, to solve the presented issue, the network of the multilayer perceptron type with one hidden layer, was designed and trained, see Fig. 9.

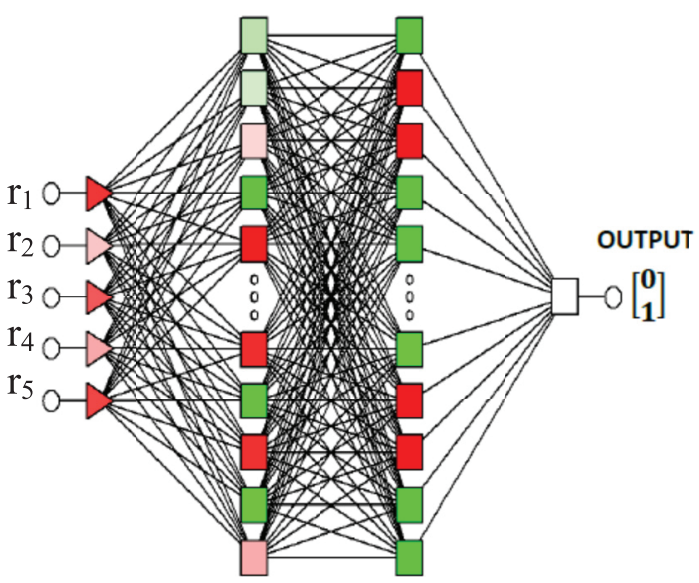

Fig. 9 Topological diagram of neural classifier of states 
The classifier, sending to network's input, the vector $r=\left[r_{1}\right.$, $r_{2}, r_{3}, r_{4}, r_{5}$ ], triggers activation of one neuron of output layer - the value "True” (1) in the case of identification of the dedicated class of states, or the value „False” (0) - in the opposite case.

The learning sets intended for training the classifiers were worked out on the basis of the assumption that a change, by less than $10 \%$, in values of particular classifiers, which results in transition of engine to a given class of states $S_{i}$ (Tab. 2 , row $3 \div 9$ ), triggers the response „False “ at classifier's output . Otherwise, the response „True” is obtained at neural network's output.

The training, validation and test of the classifier, based on the learning set, showed its very good matching and negligible number of erroneously classified cases (below $1 \%$ during the testing phase).

\section{TEST RESULTS OF NEURAL MODELS}

The working-out of particular networks and positive completion of their training made it possible to test the presented system with the use of the testing set of simulated, determined cases of values of the exhaust gas temperature tg1 and the concentration of nitrogen oxides in exhaust gas $C_{\mathrm{NOx}}$, concentration of carbon oxide in exhaust gas, $C_{\mathrm{CO}}$, concentration of hydrocarbons in exhaust gas, $C_{\mathrm{HC}}$, and concentration of oxygen in exhaust gas, $C_{\mathrm{O} 2}$.

The set of test cases containing 5000 sets of values (1000 cases for each of the class of states) were worked out on the basis of the prior obtained approximating polynomials which were randomly changed in each of the set by using a generator of pseudo-random numbers. The change concerned values of all the parameters appearing there, within the range of $\pm 5 \%$;

The presented procedure had to show first of all susceptibility of the system on disturbances, and consequently, its potentially lower or greater usefulness for implementation in real ship power plant conditions. Fig. 10 shows an error matrix for the case of the class of states $\mathrm{S}_{1}$, and Tab. 4 summarizes generally results of the tests.

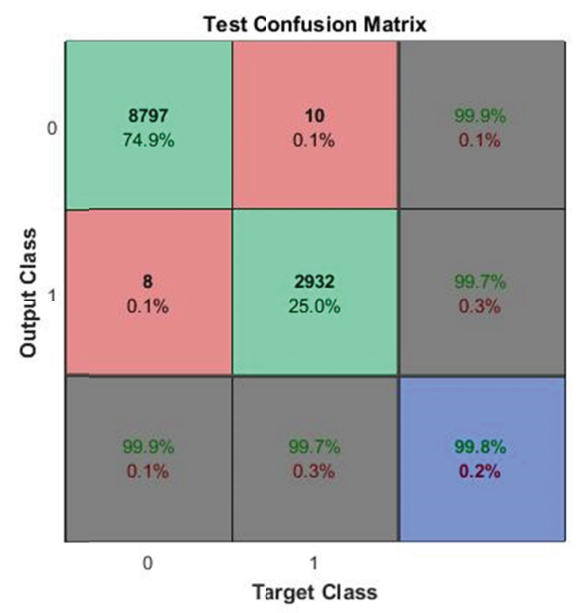

Fig. 10 State classifier's error matrix - the class of states $S_{1}$
Tab. 4 Results of testing the neural system for detection and location of errors

\begin{tabular}{|c|c|c|}
\hline $\begin{array}{c}\text { Subset of testing } \\
\text { set }\end{array}$ & $\begin{array}{c}\text { Correctly classified } \\
\text { state } \\
\text { (number of cases } \\
(\%)\end{array}$ & $\begin{array}{c}\text { Erroneously } \\
\text { classified state } \\
\text { (number of cases } \\
(\%)\end{array}$ \\
\hline State $s_{1}$ & 99,8 & 0,2 \\
\hline State $s_{2}$ & 98,4 & 1,6 \\
\hline State $s_{3}$ & 99,3 & 0,7 \\
\hline State $s_{4}$ & 98,9 & 1,1 \\
\hline State $s_{5}$ & 99,5 & 0,5 \\
\hline Mean & 99,18 & 0,82 \\
\hline
\end{tabular}

\section{SUMMARY}

The example investigation results, i.e. the values obtained during active experiment, indicate that the proposed "on-line" system for detection and location of failures correctly identifies a given class of engine states. From practical point of view its quality may be called excellent.

However it may also seem that specificity of use of especially responsible power systems such as ship power plant and its functional subsystems require higher percentage values of correct classification than those shown in Tab. 4 .

Another issue is empirical verification of the presented system. In the considered cases the set of data was relatively homogenous because it was obtained by means of algebraic relationships.

In case of investigations carried out directly on a real object, obtained results may appear quite different, that obviously requires to carry out further investigations whose main condition is to realize in practice, as to its program solutions and instrumentation, the system discussed in this paper.

\section{BIBLIOGRAPHY}

1. Korbicz J., Kościelny J.M., Kowalczuk Z., Cholewa W.: Diagnostics of processes. Models. Artificial intelligence methods. Applications. (in Polish), Warsaw, WNT 2002.

2. Kropiwnicki J., Kneba Z.: Carbon dioxide potential reduction using Start-Stop system in a car. Key Engineering Materials, Vol. 597 (2014), s. 185-192.

3. Kufel T.: Econometrics. Solving Problems Using GRETL Software, in Polish, Polish Scientific Publishers PWN, Warszawa. 2007. 
4. Kukiełka L.: Basics of Engineering Research, in Polish, Polish Scientific Publishers PWN, Warszawa 2002.

5. Markowski J., Pielecha J., Jasiński R., Kniaziewicz T., Wirkowski P.:Development of alternative ship propulsion in terms of exhaust emissions. 1st International Conference on the Sustainable Energy and Environment Development (SEED 2016), E3S Web of Conferences 10, 00140 (2016)

6. Piaseczny L. Zadrąg R.: The influence of selected damages of engine SI type on the changes of emission of exhaust gas components, Diesel Engines, Opole 2009.

7. Polański Z.: Design of Experiments in Technology, Polish Scientific Publishers PWN, Warszawa 1984.

8. Rudnicki J., Zadrąg R.: Problems of modelling toxic compounds emitted by a marine internal combustion engine for the evaluation of its structure parameters. Combustion Engines No.3/2015(162), ISSN 2300-9896, Poznań 2015.

9. Skoundrianos E.N., Tzafestas S.G.: Fault diagnosis via local neural networks. Mathematics and Computers in Simulation 60 (2002) 169-180. Elsevier Science 2002.

10. Tadeusiewicz R.: Neural networks (in Polish). Warszawa, Akademicka Oficyna Wydawnicza RM 1993.

11. Zadrąg R.: Criteria for the selection of the diagnostic parameter for diagnosis of marine diesel engine, LOGISTYKA No. 4/2010, ISSN 1231-5478, Poznań 2010.

12. Zadrąg R.: The Multi-equational models of leakproofness of charge exchange system of ship engine, (in Polish), in monograph 'Gaseous engines - selected issues" edited by Adam Dużyński, University of Czestochowa Publishing, ISBN 978-83-7193-461-2, ISSN 0860-501., Częstochowa 2010.

13. Zadrąg R. et al.: Identification models for the technical condition of the engine on the basis of exhaust component emissions, in Polish, The report of the research project no. 4T12D 055 29, AMW, Gdynia 2008.

14. Zadrąg R., Zellma M.: The usage of multi-equation models in analysis of dynamic process in marine diesel engine research. JOURNAL OF POLISH CIMAC, Vol.7, No 1, ISSN 1231-3998, str. 295-304, Gdańsk 2012.

15. STATISTICA Neural NetworksTM. Prze-wodnik problemowy. StatSoft, Kraków 2001.

16. Neural Network Toolbox ${ }^{\mathrm{m}}$. Matlab. User's guide. The MathWorks, Inc. 2014.

\section{CONTACT WITH THE AUTHOR}

\author{
Jacek Rudnicki \\ Ryszard Zadrąg \\ Gdańsk University of Technology \\ Faculty of Ocean Engineering and Ship Technology \\ 11/12 Narutowicza St. \\ 80 - 233 Gdańsk \\ Poland
}

